\title{
An Experimental Test of the Impact of Varying Questionnaire Response Format on Prevalence Rates for Sexual Violence Victimization and Perpetration
}

\author{
RaeAnn E. Anderson \\ University of North Dakota, raeann.anderson@UND.edu \\ Kelly Cuccolo
}

\section{How does access to this work benefit you? Let us know!}

Follow this and additional works at: https://commons.und.edu/psych-fac

Part of the Psychology Commons

\section{Recommended Citation}

RaeAnn E. Anderson and Kelly Cuccolo. "An Experimental Test of the Impact of Varying Questionnaire Response Format on Prevalence Rates for Sexual Violence Victimization and Perpetration" (2021). Psychology Faculty Publications. 43.

https://commons.und.edu/psych-fac/43

This Article is brought to you for free and open access by the Department of Psychology at UND Scholarly Commons. It has been accepted for inclusion in Psychology Faculty Publications by an authorized administrator of UND Scholarly Commons. For more information, please contact und.commons@library.und.edu. 


\title{
An Experimental Test of the Impact of Varying Questionnaire Response Format on Prevalence Rates for Sexual Violence Victimization and Perpetration \\ (C) The Author(s) 202I \\ Not the version of record. \\ The version of record is available at DOI: I0.I I 77/088626052 I I064239 https://journals.sagepub.com/home/jiv
}

Journal of Interpersonal Violence 202I, Vol. (0)(0) I-22

\author{
RaeAnn E. Anderson, $\mathrm{PhD}^{\prime} \oplus$ and Kelly Cuccolo, $\mathrm{PhD}^{2}$
}

\begin{abstract}
Objective: This study examined the impact of a dichotomous versus scaled response format on prevalence rates of sexual violence perpetration and victimization, thus conceptually replicating Hamby et al., 2006 and extending those findings to the context of sexual violence. Methods: Two samples were recruited from Amazon Mechanical Turk and were randomly assigned to either a dichotomous or scaled response format of the same questionnaire. Sample I was used to examine perpetration and received a perpetration specific version of the Post-Refusal Sexual Persistence Scale (PRSPS). Sample 2 was used to examine victimization and received a victimization specific version of the PRSPS. Results: Men and women who received the scaled response format reported significantly more incidents of sexual perpetration, and for each type of tactic studied, on the order of 1.7-9x more frequently. The association between response format condition and prevalence rates of sexual violence victimization was significant only for men ( 23.0 vs $39.4 \%$ ) and for the tactic of verbal coercion ( 30.1 vs $41.5 \%)$, with the scaled response format producing greater responding. Conclusions: The response format of sexual violence items can significantly alter prevalence rates of sexual violence perpetration, with scaled response formats producing greater endorsements than dichotomous formats. Response format also appears to impact prevalence rates of sexual violence victimization, particularly for men.
\end{abstract}

\section{Keywords}

rape, sexual assault, sexual violence, aggression, perpetration, assessment, measurement

\footnotetext{
'Department of Psychology, University of North Dakota, Grand Forks, ND, USA
}

\section{Corresponding Author:}

RaeAnn E. Anderson, Department of Psychology, University of North Dakota, 50I N Columbia Road, Grand Forks, ND 58202-8380, USA.

Email: raeann.anderson@UND.edu 
Journal of Interpersonal Violence $0(0)$

\section{An Experimental Test of the Impact of Varying Questionnaire Response Format on Prevalence Rates for Sexual Violence Victimization and Perpetration}

Sexual violence affects approximately one in five American women (Walters et al., 2011), nearly as many men (Stemple \& Meyer, 2014), and causes a vast range of deleterious health consequences (Koss, 1993). Sexual violence victimization is the experience of sexual activity without consent; in contrast, sexual violence perpetration is the act of obtaining sexual activity without someone's consent (Basile et al., 2014). Since the 1970's sexual violence has been a serious topic of research (Koss et al., 1987), and the research base appears to be growing (Anderson et al., 2019). In spite of this proliferation of interest and research, innovations in the methodology of studying of sexual violence has been largely stagnant, with measures developed in the 1970s still in use (Hamby, 2014). Indeed, review studies often inadvertently underscore the lack of precision in measurement tools; a recent systematic review shows the estimates of sexual violence perpetration in men range from $6.7-92.0 \%$ (Anderson et al., 2019) and men's victimization from 2 - 70\% (Peterson et al., 2010). Consistent with repeated calls in the literature (Grych \& Hamby, 2014; Krahé \& Vanwesenbeeck, 2015) the goal of this study is to improve precision in sexual violence research by examining how varying the response format of otherwise identical sexual violence questionnaires impacts reported prevalence rates.

\section{Characteristics of Sexual Violence Measurement}

Research suggests that measures of sexual violence should at minimum include elements that assess consent, the tactic of coercion, and the sexual act that was coerced (Cook et al., 2011). An impressive body of research demonstrates the importance of using behaviorally-specific language to assess sexual experiences in the context of violence (Fisher et al., 2005; National Research Council, 2014). Yet, research is just beginning to examine how to optimize the assessment of the remaining elements: consent and tactics of coercion. Further, a growing body of research suggests that the design features of questionnaires can impact associated prevalence rates. Characteristics such as the mode participants complete questionnaires in (paper vs. computer, McCallum \& Peterson, 2017), what participants believe the topic of the study is influence respondent behavior (Anderson, Carstens Namie, et al., 2021), even for innocuous behaviors such as how much television is watched (Schwarz et al., 1991). These effects may or may not be further magnified when considering stigmatized behaviors. For example, participants disclose more experiences of interpersonal violence in surveys on health than surveys of crime (National Research Council, 2014); researchers suggest the survey context of "crime" impacts how participants label their own experiences and social norms are such to discourage seeing physical assault within the home as crime. As such, there is still a great deal to be learned about how to best assess sexual violence both in terms of necessary elements (consent, tactics, sexual experiences) and in terms of questionnaire /survey design (Krebs, 2014).

\section{Importance of Response Formats}

Changing the response format of a questionnaire is one of the more common alterations made to standardized questionnaires in sexual violence research (Anderson et al., 2019); we hypothesize this is so common because it is one way that investigators can "simplify" a complex questionnaire. In addition, response formats are not proprietary, so investigators may feel safe altering response formats without infringing on copyrights or vastly altering the psychometric properties of a questionnaire (whether this truly impacts 
psychometric properties or not is another question). The following narrative review of some current violence questionnaires reveals a wide range of possible response formats. The 2007 Sexual Experiences Surveys (Short Forms Victimization and Perpetration: Koss et al., 2007) use a scaled response format of 0, 1, 2 ,3+; the Revised Conflict Tactics Scales uses a once, twice, 3-5 times, 6-10 times, 11-20 times, more than 20 times response format for the past year and then "not in the past year, but it did happen before" to assess past-year intimate partner violence (Straus et al, 1996). The Partner Victimization Scale, developed in part to correct some of the weaknesses of the Conflict Tactics Scales, uses fewer items and a simplified response format of "yes/no" (Bell et al., 2018). The Sexual Aggression and Victimization Scale (SAV-S) one of the few questionnaires to be submitted to extensive cross-cultural development and testing uses a "never", "once" or "more than once" response format for each item (Krahé et al., 2015) although this has been simplified to yes/no in recent studies (Schuster et al., 2020). The Sexual Strategies Scale revises the original response format of the Post-Refusal Sexual Persistence Scale from writing in the number of times the experience occurred to simply checking a box indicating the experience has occurred at some point (Strang et al., 2013; Struckman-Johnson et al., 2003). The Reproductive Coercion Scale, perhaps the first questionnaire of its kind, published in 2017, uses a dichotomous response format (McCauley et al., 2017). A review of Psychology of Violence articles published in the year 2019 suggest that approximately 21 out of 53 studies used a dichotomous response format to assess violence, quantifying the commonality of a dichotomous response format.

Yet, using a dichotomous response format may underestimate prevalence rates while using a scaled frequency response format may increase disclosures and thus result in higher prevalence rates (Anderson et al., 2019; DiLillo et al., 2006; Strang et al., 2013). The hypothesized mechanism behind this effect is that a scaled response format produces a normalizing effect for participants, suggesting the stigmatized behaviors described are common, thus facilitating greater disclosure, or alternatively, allowing participants to re-appraise a previously ambiguous event. is effect of normalizing is consistent with social cognition research suggests that participants see the mid-point of the scale as the "average" response (Schwarz et al., 1991). One experimental study further supports this idea. Hamby et al., (2006) randomly assigned participants to receive either a dichotomous or scaled frequency questionnaire response format on otherwise identical versions of the Revised Conflict Tactics Scales. They found an effect size of Cohen's $d \approx .4$ for the effect of questionnaire response format on sexual violence prevalence rates such that the scaled response format increased the reporting of sexual violence victimization and perpetration in intimate relationships compared to a dichotomous yes/no format. This corresponded to a difference of 7.5-22.5 percentage points in prevalence rates. They also found effects for gender and type of violence; the effect of questionnaire response format was larger for men compared to women and for sexual violence compared to the other types of intimate partner violence studied. This pattern of findings is consistent with the social norms around rape in American culture; rape is seen as a "woman's issue" thus, men would be more susceptible to certain experimental manipulations (Hockett et al., 2016).

\section{Current Study}

To our knowledge, only one prior experimental study has tested the impact of questionnaire response formats (Hamby et al., 2006) although, multiple studies assessing childhood sexual abuse (DiLillo et al., 2016), intimate partner violence (Bell et al., 2018), and sexual violence perpetration (Anderson et al., 2019) have suggested response formats may affect prevalence rates. Thus, the goal of this study is to conceptually replicate Hamby et al., (2006) but instead using sexual violence items from the Post-Refusal Sexual Persistence Scales (PRSPS: Struckman-Johnson et al., 2003). We chose the PRSPS items rather than Sexual 
Journal of Interpersonal Violence $0(0)$

Experiences Survey or Revised Conflict Tactics Scales items given that PRSPS items are among the briefest of sexual violence questionnaires that are still supported with validity data. We did not test the Sexual Experiences Survey items because they are far more complex in reading level (Testa et al., 2015), which can trigger non-response (Swain et al., 2008) thereby potentially altering prevalence rates. Our research questions/hypotheses are:

1. Participants randomly assigned to the scaled questionnaire response format will disclose more incidents and therefore produce larger prevalence rates (numerically and statistically) for sexual violence perpetration (H1a) and victimization (H1b) compared to a dichotomous response format.

2. Although Hamby et al. (2006) found a stronger effect for men, findings have been mixed as to the existence and range of these gender differences in other studies (Anderson \& Delahanty 2019; DiLillo et al., 2006).

3. Finally, we will investigate whether questionnaire response format effects are sensitive to the type of sexual violence being disclosed as assessed by the four tactics (verbal coercion; alcohol facilitated; physical force; threat of physical force) measured by the PRSPS.

\section{Methods}

\section{Participants}

Two samples were recruited from Amazon Mechanical Turk (MTurk) via the TurkPrime platform as part of a larger study that aimed to investigate the impact of tactic-first items and item-order on sexual violence prevalence rates (the pre-registration detailing the design of this study can be found on Open Science Framework). MTurk workers were only eligible to participant in this study is they had a history of highquality work (> 90\% HIT rate, i.e., completing tasks with high-quality). Prior research has suggested that high-quality MTurk responses are similar to community and college samples (Necka et al., 2016). Further, sexual violence has lasting effects across the lifespan (e.g., Choudhary et al., 2008) thus recruiting any adult population is relevant.

Sample 1 included 355 adult participants with a mean age of 32.34 (SD =7.91) who were administered perpetration items. The majority of the sample consisted of men $(52.7 \%$, women $46.8 \%$, other gender identities $0.3 \%$ ), was White (77.2\%, Black 12.4\%, Asian 9.3\%, Indigenous $0.8 \%$, Other 2.3\%), and heterosexual $(85.9 \%$, bisexual $10.1 \%$, gay/lesbian $2.5 \%$, queer or other $1.4 \%)$. Sample 2 were 293 adults who were administered victimization items. The majority were women $(53.2 \%$, men $-45.1 \%$, other gender identities - 1.7\%), White (74.1\%, Black 10.9\%, Asian 5.5\%, Multiple Race 7.6\%, Other 1.7\%) and heterosexual $(82.9 \%$, bisexual $11.6 \%$, gay/lesbian $3.8 \%$, other $1.7 \%$ ). The mean age of Sample 2 was 32.27 (SD $=8.39$ ). Note that given the small $n$, the Trans/Genderqueer identifying individuals were excluded from analyses aimed at testing hypotheses. Men and women did not differ on age in either sample, $p>.05$.

\section{Procedure}

The study was titled in TurkPrime as, "Kent State University - Questionnaires about Sexual Behavior 2" or "3", a large public university in the Midwestern United States. Those interested in completing the study were able to read a 2-3 sentence description and then redirected to Qualtrics to complete the study beginning with informed consent. Participants completed the demographics questionnaire and then were randomly assigned to complete either the dichotomous or scaled sexual violence questionnaire, in addition to one other questionnaire administered for a co-occurring study. Participants received $\$ .75$ compensation; a few participants commented this was inadequate and we suggest higher compensation in future studies. 
The Kent State University's Institutional Review Board approved the protocol. Two manuscripts have been previously published from these datasets. Data from Sample 1 and 2 were included in a study on made-topenetrate victimization (Anderson et al., 2020) and data from Sample 1 in a study on the impact of tacticfirst items (Anderson, Goodman, et al., 2021).

\section{Measures}

Cronbach's alpha is often reported as a measure of internal consistency reliability and is a good measure of internal reliability for latent constructs. However, sexual victimization is not a latent construct; there is no unobserved trait within participants that causes their victimization (Hulme, 2007; Koss et al., 2007), rather victimization is caused by external forces, specifically, by the perpetrator. Sexual perpetration, on the other hand, may be a latent construct although we are unaware of any published papers which support this empirically. Thus, in the following discussion of psychometric properties we do not report internal consistency and instead focus our judgments of reliability on test-retest reliability data (Diamantopolous et al., 2008).

Post-Refusal Sexual Persistence Scales (PRSPS: Struckman-Johnson, Struckman-Johnson, \& Anderson, 2003). The PRSPS beings with a comprehensive definition of sexual behavior and a behavioral operationalization of consent, "Since age 14, which of the following strategies have you used to convince someone to have sex (oral, anal, or vaginal intercourse) or sexual contact (kissing, making out, touching private parts or genitals) with you after they have indicated "no" to your advances." Below this instruction each item is listed; each item describes a tactic of coercion such as, "tying them up." The full form has 19 tactics. Initial research has indicated good construct validity of PRSPS items; 80\% of participants who endorsed items subsequently described incidents that were consistent with sexual assault (Struckman-Johnson et al., 2003). A recent study shows good evidence of test-retest reliability in a MTurk sample (Anderson, Garcia, et al., 2021). To see the items tested in this study, consult Table 1.

Two brief versions of the PRSPS were used - a victimization version (PRSPS-V) and a perpetration version (PRSPS-P), consistent with Dyar et al., 2019. To create breadth in the type of sexual violence assessed, four items from the full scale that represent the most commonly endorsed item from each tactic category based on prior data collected in our laboratory. The four tactic categories included on the PRSPS common to many other questionnaires include - verbal coercion, substance use facilitation, threats of physical harm, and use of physical harm. In the current study, we randomly assigned participants to either a dichotomous (i.e., yes/no) or scaled questionnaire response format (i.e., 0, 1, 2-5 times, 6-9 times, 10+ times). In order to differentiate from the victimization items, the instruction, "these questions are about things you may have done to someone else," was to the PRSPS-P items. To differentiate from the perpetration questions, the brief instruction, "these questions are about things that may have happened to you" was added to the PRSPS-V.

\section{Power Analysis}

A priori power analyses were estimated using the results from Hamby et al. (2006) and G*Power. Hamby's results estimated an effect size of Cohen's $d=.4$ for the effect of response format on sexual violence outcomes; this converts to an effect size of $w \approx .25$. A Cohen's $d$ of .4 , and a $w$ of approximately .25, can both be considered small to medium effects. Utilizing G*Power, an effect size of $w \approx .25, \alpha=.05, d f=1$, 
Journal of Interpersonal Violence $0(0)$

Table I. Items Tested

\begin{tabular}{ll}
\multicolumn{1}{c}{ Victimization } & \multicolumn{1}{c}{ Perpetration } \\
\hline $\begin{array}{l}\text { These questions are about things that may } \\
\text { have happened to you. }\end{array}$ & $\begin{array}{l}\text { These questions are about things you may have } \\
\text { done to someone else. }\end{array}$
\end{tabular}

In the past, which of the following strategies have you used to convince someone to have sex (oral, anal or vaginal intercourse) or sexual contact (kissing, making out, touching private parts or genitals) with you after they have indicated "no" to your advances.

How many times?

$$
0 \quad \text { I 2-5 times 6-9 times } 10+\text { times }
$$

Overwhelmed you with continual arguments or pressure

Taken advantage of you when you were too intoxicated to give consent or stop what was happening

Used physical force (twisted your arm, held you down)

Threatened to use physical force
Overwhelmed them with continual arguments or pressure

Taking advantage of the fact that they are drunk or high

Harming them physically (twisting their arm, holding them down, etc.) Threatening to harm them physically

Note: The introductory text defining sexual activity is modified from the first publication of the Post-Refusal Sexual Persistence Scales.

and Power $=.80$, a sample size of 126 would be needed to accurately detect an effect. Thus, with our sample sizes of 355 (Sample 1) and 293 (Sample 2), our primary hypotheses are well-powered.

Analytic Plan and Data Quality. Participants who completed less than $80 \%$ of the study (consent and zero complete questionnaires) were excluded outright. This criterion excluded 23 participants from Sample 1 and 2 from Sample 2. Next, data in Sample 1 was first examined for missing cases, which were minimal (i.e., $<10 \%)$, as was Sample $2(<5 \%)$. Following, we used an available-item-analysis approach. Instances of missing data were managed by inserting the modal score, in this case, zero. This simple approach is appropriate and comparable to more complex approaches for larger datasets, where missing data is minimal (Parent, 2013). Participants who were excluded outright for completing less than $80 \%$ of the study overlapped highly with those who failing attention checks suggesting this approach may be as optimal for data quality as attention checks, which do not operate as intended (Hauser \& Schwarz, 2015).

To evaluate differences by response format condition, cross-tabulations and chi-square analyses were calculated to assess how prevalence rates may have differed by condition. Given the multiple comparisons within the cross-tab analyses related to Hypotheses 1-4, p-values were adjusted using the Bonferonni method. For organizational purposes, hypotheses related to perpetration are labeled "a" while hypotheses related to victimization are labeled with a "b." 


\section{Results}

\section{Sample I - Perpetration}

Research Question Ia: Questionnaire Response Format Condition. In the full sample, $18.0 \%$ of participants endorsed perpetration $(n=64)$. Within the dichotomous questionnaire response format condition, $11.6 \%$ $(n=19)$ of respondents endorsed perpetration, whereas in the scaled questionnaire response format condition, the endorsement rate was $23.6 \%(n=45)$. The association between condition and endorsement of perpetration was significant, $\chi 2(1)=8.562, \mathrm{p}=.003$, Cramer's V was .155. Post-hoc achieved power analyses were also conducted to determine observed power. Using the percent endorsement of perpetration in the scaled and dichotomous formats as the values for alternative hypotheses resulted in an estimated effect size of $w=.34$, a medium effect size.

Research Question 2a: Gender. Further analysis of this effect suggests questionnaire response format affects both men, $\chi^{2}(1)=4.389, p=.036$, and women, $\chi^{2}(1)=4.010, p=.045$, see Table 2 . Approximately $18.8 \%$ of men in the dichotomous questionnaire response format condition reported perpetration compared to $32.4 \%$ who reported perpetration in the scaled questionnaire response format condition. For women, $3.8 \%$ reported perpetration in the dichotomous questionnaire response format condition, and $12.5 \%$ reported perpetration in the scaled condition.

Table 2. Endorsement of Perpetration by Gender and Sexual Identity within each Questionnaire Response Format Condition and Tactic

\begin{tabular}{|c|c|c|c|c|c|}
\hline Group & $\begin{array}{l}\text { Dichotomous ( } n \text { per } \\
\text { condition) }\end{array}$ & $\begin{array}{l}\text { Scaled ( } n \text { per con- } \\
\text { dition) }\end{array}$ & $\chi^{2}$ & $\begin{array}{l}P \\
\text { value }\end{array}$ & $\begin{array}{l}\text { Cramer's } \\
\text { V }\end{array}$ \\
\hline Men & $\begin{array}{l}18.8 \% \\
n=16\end{array}$ & $\begin{array}{l}32.4 \% \\
n=33\end{array}$ & 4.389 & .036 & .153 \\
\hline Women & $\begin{array}{l}3.8 \% \\
n=3\end{array}$ & $\begin{array}{l}12.5 \% \\
n=11\end{array}$ & 4.010 & .045 & .154 \\
\hline Tactic & $\begin{array}{c}\text { Dichotomous ( } n \text { per } \\
\text { condition) }\end{array}$ & $\begin{array}{l}\text { Scaled ( } n \text { per con- } \\
\text { dition) }\end{array}$ & $\chi^{2}$ & $\begin{array}{l}P \\
\text { value }\end{array}$ & $\begin{array}{c}\text { Cramer's } \\
\mathrm{V}\end{array}$ \\
\hline Verbal Coercion & $\begin{array}{c}6.7 \% \\
n=11\end{array}$ & $\begin{array}{l}16.8 \% \\
n=32\end{array}$ & 8.366 & .004 & .154 \\
\hline Alcohol Facilitated & $\begin{array}{l}9.1 \% \\
n=15\end{array}$ & $\begin{array}{l}17.8 \% \\
n=34\end{array}$ & 5.555 & .018 & .125 \\
\hline $\begin{array}{l}\text { Threat of Physical } \\
\text { Force }\end{array}$ & $\begin{array}{l}1.8 \% \\
n=3\end{array}$ & $\begin{array}{c}9.4 \% \\
n=18\end{array}$ & 9.145 & .002 & .160 \\
\hline Physical Force & $\begin{array}{l}4.3 \% \\
n=7\end{array}$ & $\begin{array}{c}9.4 \% \\
n=18\end{array}$ & 3.583 & .058 & .100 \\
\hline
\end{tabular}

Note. Only the data of cisgender participants is displayed. 
Journal of Interpersonal Violence $0(0)$

\section{Research Question 3a: Specific Tactic Types}

Verbal Coercion. In the dichotomous questionnaire response format condition, $6.7 \%(\mathrm{n}=11)$ of participants endorsed verbal coercion, whereas in the scaled questionnaire response format condition, the $16.8 \%(\mathrm{n}=$ 32) did. This difference was significant, $\chi 2(1)=8.37, \mathrm{p}=.004$.

Alcohol-facilitated. Within the dichotomous questionnaire response format condition, $9.1 \%(\mathrm{n}=15)$ of participants endorsed alcohol-facilitated sexual violence; in the scaled questionnaire response format condition $17.8 \%(n=34)$ did. This difference was significant, $\chi 2(1)=5.56, p=.018$.

Threat of Physical Force. Within the dichotomous questionnaire response format condition, $1.8 \%(\mathrm{n}=3)$ of respondents endorsed threat of physical force, whereas in the scaled questionnaire response format condition $9.4 \%(n=18)$ did. This difference was significant, $\chi 2(1)=9.145, \mathrm{p}=.002$.

Use of Physical Force. Within the dichotomous questionnaire response format condition, $4.3 \%(n=7)$ of respondents endorsed use of physical force whereas in the scaled questionnaire response format condition $9.4 \%(\mathrm{n}=18)$ did. The relationship between response format and use of physical force was not significant, $\chi 2(1)=3.58, \mathrm{p}=.058$.

\section{Sample 2 - Victimization}

Research Question Ib: Questionnaire Response Format Condition. In the full sample, $45.7 \%$ of participants endorsed victimization $(\mathrm{n}=134)$. The association between questionnaire response format condition and endorsement of victimization was not significant according to the chi-square test, $\chi 2(1)=3.322 \mathrm{p}=.068$, Cramer's V was .106, effect size $w=.12$ (a small effect size), Power $=.51$. Within the dichotomous questionnaire response format condition, $40.4 \%(n=59)$ of respondents endorsed victimization, whereas, in the scaled questionnaire response format condition, the endorsement rate was $51.0 \%(\mathrm{n}=75)$.

Research Question 2b: Gender. The association between questionnaire response format condition and prevalence rate of victimization was significant for men, $\chi^{2}(1)=4.110, p=.043$, but not for women, $\chi^{2}(1)=$ $1.109, p=.292$. Approximately $23.0 \%(n=14)$ of men in the dichotomous questionnaire response format condition reported victimization compared to $39.4 \%(n=28)$ who reported victimization in the scaled questionnaire response format condition. Effect sizes were small, see Table 3.

\section{Research Question 3b: Specific Tactic Types}

Verbal Coercion Endorsement. Within the dichotomous questionnaire response format condition, $30.1 \%$ (n $=44$ ) of respondents endorsed verbal coercion, whereas in the scaled questionnaire response format $41.5 \%$ $(\mathrm{n}=61)$ did. This difference was significant, $\chi^{2}(1)=4.11, \mathrm{p}=.043$, see Table 3 .

Alcohol-facilitated. In the dichotomous condition, $21.9 \%(n=32)$ of respondents endorsed alcohol-facilitated sexual victimization; in the scaled questionnaire response format condition $28.6 \%(\mathrm{n}=42)$ did. The 
Table 3. Endorsement of Victimization by Gender and Sexual Identity within each Questionnaire Response Format Condition and Tactic

\begin{tabular}{|c|c|c|c|c|c|}
\hline Group & $\begin{array}{l}\text { Dichotomous ( } n \text { per } \\
\text { condition) }\end{array}$ & $\begin{array}{l}\text { Scaled ( } n \text { per con- } \\
\text { dition) }\end{array}$ & $\chi^{2}$ & $\begin{array}{l}P \\
\text { value }\end{array}$ & $\begin{array}{l}\text { Cramer's } \\
\text { V }\end{array}$ \\
\hline Men & $\begin{array}{l}23.0 \% \\
n=14\end{array}$ & $\begin{array}{l}39.4 \% \\
n=28\end{array}$ & 4.110 & .043 & .176 \\
\hline Women & $\begin{array}{l}52.4 \% \\
n=43\end{array}$ & $\begin{array}{l}60.8 \% \\
n=45\end{array}$ & 1.109 & .292 & .084 \\
\hline Tactic & $\begin{array}{l}\text { Dichotomous ( } n \text { per } \\
\text { condition) }\end{array}$ & $\begin{array}{l}\text { Scaled (n per con- } \\
\text { dition) }\end{array}$ & $\chi^{2}$ & $\begin{array}{c}p \\
\text { value }\end{array}$ & $\begin{array}{c}\text { Cramer's } \\
\mathrm{V}\end{array}$ \\
\hline Verbal Coercion & $\begin{array}{l}30.1 \% \\
n=44\end{array}$ & $\begin{array}{l}4 I .5 \% \\
n=6 I\end{array}$ & 4.11 & .043 & .118 \\
\hline $\begin{array}{l}\text { Alcohol } \\
\text { Facilitated }\end{array}$ & $\begin{array}{l}21.9 \% \\
n=32\end{array}$ & $\begin{array}{l}28.6 \% \\
n=42\end{array}$ & 1.718 & .190 & .077 \\
\hline $\begin{array}{l}\text { Threat of Physical } \\
\text { Force }\end{array}$ & $\begin{array}{c}8.9 \% \\
n=13\end{array}$ & $\begin{array}{l}11.6 \% \\
n=17\end{array}$ & .564 & .453 & .044 \\
\hline $\begin{array}{l}\text { Physical } \\
\text { Force }\end{array}$ & $\begin{array}{l}14.4 \% \\
n=21\end{array}$ & $\begin{array}{l}18.4 \% \\
n=27\end{array}$ & .849 & .357 & .054 \\
\hline
\end{tabular}

Note. Only the data of cisgender participants is displayed.

between condition and endorsement of alcohol-facilitated sexual victimization was not significant, $\chi 2$ (1) $=1.72, \mathrm{p}=.190$.

Threat of Physical Force Endorsement. In the dichotomous questionnaire response format condition, $8.9 \%$ $(\mathrm{n}=13)$ of respondents endorsed threat of physical force whereas, in the scaled questionnaire response format condition, $11.6 \%(\mathrm{n}=17) \mathrm{did}$. This difference was not significant, $\chi 2(1)=.56, \mathrm{p}=.453$.

Physical Force Endorsement. Within the dichotomous questionnaire response format condition, $14.4 \%(\mathrm{n}=$ 21) of respondents endorsed physical force, whereas, in the scaled questionnaire response format condition $18.4 \%(\mathrm{n}=27)$ did. The association between condition and endorsement of physical force was not significant, $\chi 2(1)=.849, \mathrm{p}=.357$.

\section{Follow-up Analyses}

Given the above pattern of findings indicating larger prevalence rates in the scaled response format condition, we were interested in further analyses to ascertain whether there was a pattern of responses within the scaled condition. We examined how many participants endorsed the response categories of "1" vs. " $2-5$, 
Journal of Interpersonal Violence $0(0)$

6-9, and 10+ times" in the scaled condition and compared these numbers to the relative differences between the two conditions. The relative difference between the conditions represents participants that are "new" cases; in other words, participants who would have been labeled as lacking victimization or perpetration experiences in the dichotomous condition.

If the most frequent response in the scaled condition is participants responding " 1 ," that suggests that a scaled response format of any type may be sufficient to facilitate new disclosures for the otherwise hesitant because marking " 1 " is the most similar to a simple "yes". We hope that these analyses inspire future follow-up research by providing helpful, descriptive data.

We focused these analyses on the perpetration data and the tactics of sexual violence, rather than gender or sexual identity, given the tactics are more associated with perceptions of severity than gender (Abbey et al., 2004), are consistent across victimization and perpetration, and are associated with disclosure to others (Ullman, 1996).We present this data descriptively in Table 4 for categories only in which there were ten or more positive cases.

For three of the four tactics assessed, the relative difference between conditions appears to have occurred more often by participants selecting a response of " $2+$ " than by participants selecting " 1 ". In other words, numerically, more participants chose a response of " $2+$ " than " 1 " for verbal coercion victimization, alcohol-facilitated victimization, alcohol-facilitated perpetration, threats of force perpetration, and physical force perpetration. In most of these same conditions, the number of participants that chose " $2+$ " is numerically greater than the relative difference between conditions. For example, in the verbal coercion victimization condition, the relative difference between the conditions was 17 responses; in the scaled condition 17 participants chose " 1 " and 44 chose $2+$ ". This is surprising as one would expect the difference between conditions to be distributed unequally and mostly in the " 1 " category if the increase in disclosures in the scaled condition were due solely to re-evaluating infrequent or unusual experiences.

Table 4. Analysis of Endorsement Patterns in the Scaled Response Format Condition

\begin{tabular}{|c|c|c|c|c|c|}
\hline & $\begin{array}{l}\text { Dichotomous } \\
\text { prevalence rate }\end{array}$ & $\begin{array}{l}\text { SC prevalence } \\
\text { rate }\end{array}$ & $\begin{array}{c}n \text { difference } \\
\text { between con- } \\
\text { ditions }\end{array}$ & $\begin{array}{l}n \text { endorsing } \\
\text { "I" in SC } \\
\text { condition }\end{array}$ & $\begin{array}{l}n \text { endorsing } 2+\text { in } \\
\text { SC condition }\end{array}$ \\
\hline \multicolumn{6}{|l|}{ Victimization } \\
\hline Verbal Coercion & $30.1(n=44)$ & $4 I .5(n=61)$ & $n=17$ & $n=17$ & $n=44$ \\
\hline Alcohol Facilitated & $21.9 \%(n=32)$ & $28.6 \%(n=42)$ & $n=10$ & $n=15$ & $n=27$ \\
\hline \multicolumn{6}{|l|}{ Perpetration } \\
\hline Verbal Coercion & $6.7 \%(n=11)$ & $16.8 \%(n=32)$ & $n=21$ & $n=16$ & $n=16$ \\
\hline Alcohol Facilitated & $9.1 \%(n=15)$ & $17.8 \%(n=34)$ & $n=19$ & $n=14$ & $n=20$ \\
\hline Threats of Force & $1.8 \%(n=3)$ & $9.4 \%(n=18)$ & $n=15$ & $n=4$ & $n=14$ \\
\hline Physical Force & $4.3 \%(n=7)$ & $9.4 \%(n=18)$ & $n=11$ & $n=5$ & $n=13$ \\
\hline
\end{tabular}

Note. Only the data of cisgender participants is displayed. 


\section{Discussion}

Given the wide breadth of estimates for sexual violence victimization and perpetration, greater precision in measurement tools is needed and research that supports understanding best practices is therefore necessary. This study represents one of few attempts to experimentally investigate the impact of questionnaire response formats on reported prevalence rates for sexual violence, a component of understanding best practices for sexual violence measurement. The effect of questionnaire response formats, though statistically sometimes small, was practically astounding to us. Simply changing the questionnaire response format dramatically changed reported prevalence rates in several analyses. For example, for men reporting perpetration, using a scaled response format increased perpetration reports by 1.7-9 times compared to the dichotomous condition (RQ1a).

Participants randomly assigned to the scaled questionnaire response format disclosed more incidents and therefore produced larger prevalence rates for sexual violence perpetration (RQ1a) but not victimization (RQ1b). However, gender further clarifies the effects of response format on prevalence rates; victimization reports did change for men, but not women (RQ2). This gender difference is consistent with research on stigma and shame regarding sexual violence victimization though to be clear, shame and stigma is assigned to rape survivors generally. There is a significant stigma surrounding men's sexual violence victimization (Hlavka, 2017), and this stigma may deter men from endorsing experiences with sexual violence using a dichotomous response format.

We also examined questionnaire response format condition effects by tactic (RQ3). For perpetration, the questionnaire scaled response format condition increased reporting of every tactic, three out of four times with statistical significance (Bonferroni correction). Further, exploratory post-hoc analyses suggest that for perpetration, the scaled response format facilitated greater disclosure by participants choosing larger number responses, "2-5", "6-9" or " $10+$ " rather than choosing "1". Perhaps this suggests that for perpetration, a stronger cue (e.g., inclusion of large numbers) is needed to facilitate disclosure. The presence of "2-5,6-9, 10+ times" suggests to participants that it is normal to engage in behavior multiple times (Schwarz et al., 1991).

Overall, our results are potentially consistent with Strang \& Peterson's (2016) suggestion that underreporting remains a significant problem for sexual violence measurement as this study did not actually change perpetration behavior or past experiences of sexual victimization but did, apparently, change the reporting of it. Indeed, researchers should be mindful when changing the response options of scales as participants may be sensitive to such changes. Both dichotomous and continuous/scaled response formats have been critiqued in the psychometric literature for producing response bias, with dichotomous scales specifically being susceptible to the creation of distorted results and continuous/scaled response formats being critiqued for assuming the applicability of equal-interval scaling (Clark \& Watson, 1995; Comrey, 1988). Comrey (1988) remains critical of dichotomous scales, arguing that quantitative scales with at least five response categories are optimal because they will produce a more or less continuous distribution. Additionally, dichotomous scales are less reliable than continuous scales because of difficulty participants have in choosing between the responses (which are sometimes perceived to be extreme) and as such a continuous or scaled response format may help participants perceive an event along a continuum (Comrey, 1988), seeing the midpoint response as an anchor or reference point (Schwarz et al., 1991). In other words, and as in Strang and Peterson's false pipeline study on perpetration, a scaled response format may normalize multiple instances of a behavior and overcome social desirability as a barrier to reporting (Sugarman \& Hotaling, 1997). However, this social desirability explanation is speculative and should be investigated in future research. 
Journal of Interpersonal Violence $0(0)$

Although the mechanism is unknown our findings are also consistent with recent clinical research. Bond et al., (2021) noted that a scaled response format for reporting adverse childhood events (ACEs), which includes childhood sexual abuse victimization, was more predictive of mental health outcomes compared to dichotomously formatted questionnaire. This work suggests that among people who experience multiple instances of traumatic events, such as sexual violence, a scaled response format may be useful through its increased predictive power. Clinically, a scaled response format is likely more emotionally validating to patients' experiences because they are more reflective of reality (i.e., multiple incidences of trauma).

\section{Limitations}

Although our a-priori power analyses suggested we would be well powered, our achieved power analyses suggest this was true for perpetration but not victimization analyses. Why our effect sizes were so different from Hamby et al., (2007) is unclear - but may be related to difference in the main questionnaires used - the PRSPS produced high rates of victimization for both conditions. Further, although are post-hoc analyses are suggestive of a normalizing effect for the scaled response format, they are nonexperimental analyses and, therefore, inconclusive. Indeed, a plausible alternative hypothesis is that our experimental manipulation caused participants to perceive and label their own behavior differently. Schwarz et al., (1987) suggests that the range of the response formats can influence participants to reevaluate ambiguous behavior in a manner consistent with the response scale. Thus, if participants are assuming the mid-point of a scale to be the "normal" or "average" response, they may perceive and report their own previously ambiguous (to them) behavior differently (Schwarz et al., 1987). Additionally, although we used behaviorally specific questionnaires there is still some ambiguity in what "indicated no" might mean (e.g., strictly verbal "no"). Further, the majority of both Sample 1 and 2 were White and heterosexual. Ethnic and racial minoritized individuals face additional barriers and stigma that could influence questionnaire responding (for example, see Tillman et al., 2010), as do sexual and gender minoritized individuals (Sigurvinsdoltir \& Ullman, 2016).

MTurk samples and similar professional respondent groups have different characteristics from the population and differential motives for participation. Recruiting such nonprobability samples introduces potential bias (Cornesse et al., 2020). For example, MTurk samples are not representative of those with limited internet access and sexual behaviors are different in probability samples (Erens et al., 2014); thus, replicating of these findings with different samples is recommended.

\section{Future Directions}

Examining endorsement of perpetration and victimization as a function of response format with other questionnaires is important in order to ensure the findings are not specific to the PRSPS or the Revised Conflict Tactics Scales. Indeed, the PRSPS has unique features such as being designed to examine perpetration by men and women, not measuring rape as legally defined, and asking if tactics were used "after he/she indicated 'no' to your advance' instead of using the word consent (Buday \& Peterson, 2015). It could be that because the PRSPS uses a behavioral operationalization of consent the scaled response format allows participants to acknowledge experiences wherein the consentedness of the experience was unclear or confusing to them which increased prevalence rates regardless of condition. This would be especially consistent with the ambiguity explanation as to the mechanisms of our findings. Additionally, taking a finer-grained approach to examining patterns of responding using item response theory (IRT) analyses is important. IRT would highlight the relationship between an individual's responses on individual items and the hypothesized underlying construct that is presumed to give rise to 
the response (i.e., sexual violence perpetration or victimization). It is important to note that if participants are unable to make the subtle distinctions as the options increase, reliability will decrease (Clark \& Watson, 2016); as such, more work should be done to understand participants' reactions to the response options (Clark \& Watson, 2016).

We also recommend future research investigate the likely mechanisms behind these findings. For example, examining whether perceived stigma is related to responding would test the hypothesis that a scaled response format normalizes the behaviors described and thus facilitates greater disclosure. Including assessments of social desirability may also be useful to assess biased responding in future work examining the influence of varied questionnaire response formats on perpetration and victimization endorsement. Supplementing quantitative methods with qualitative methods may also be critical to discerning participants' disclosure of both stigmatized and non-stigmatized experiences and their thought processes as to when and why specific response categories are selected. Think aloud procedures could identify what language participants see as ambiguous and whether this triggers re-appraisal of memories.

\section{Implications for Research, Practice, and Policy}

Precision in measurement is a foundational step in identifying groups at high risk for perpetration and victimization, respectively, and as such, is critical to the creation of tailored prevention programs, policies, and initiatives. Our findings suggest experimental research designs may be helpful in the practice of scale development generally and help researchers identify mechanisms underlying changes in the constructs studied. For example, randomly assigning participants to different versions of the same item, different response formats, et cetera could clarify best practices for scale development generally. For example, the measurement of depressive symptoms may be subject to many of the same response patterns noted in this paper.

Researchers should strive to be mindful of the social norms and stigma that the research environment may unwittingly communicate (via how the study is advertised, via response formats, questionnaire instructions, etc.,) on participants' willingness to items generally. This study suggests this process may be different for victimization than for perpetration and for men vs. women. This type of gender difference would affect the measurement of many psychological constructs. Multiple studies suggest that commonly used questionnaires do not fully capture men's sexual victimization experiences or women's perpetration (Anderson et al., 2020; Stemple, \& Meyer, 2014). For men, specifically, stigma may play a large role in the underreporting of experiences with sexual violence victimization (Hlavka, 2017; Weiss, 2010). In clinical settings this suggests very careful evaluation of trauma histories; in prevention and policy work this suggests additional, tailored strategies may be needed to engage men.

\section{Conclusions}

In order to appropriately focus resources and estimate the efficacy of interventions, it is critical to be able to accurately assess prevalence rates of sexual violence victimization and perpetration. Simply changing the response format impacted reported prevalence rates for sexual violence across genders, sexual identities, and type of tactic. Using a scaled response format consistently produced greater endorsement of sexual violence perpetration compared to a dichotomous response format on otherwise identical items. For men, specifically, the scaled response format also resulted in greater reported rates of sexual victimization. We recommend researchers carefully consider how modifications of any sexual violence questionnaire element may impact responses. 


\section{Declaration of Conflicting Interests}

The author(s) declared no potential conflicts of interest with respect to the research, authorship, and/or publication of this article.

\section{Funding}

The author(s) disclosed receipt of the following financial support for the research, authorship, and/or publication of this article: Dr. Anderson's work was supported by a grant from the National Institute on Alcohol Abuse and Alcoholism (5K01AA026643- 02; 5K01AA026643-03). The content is solely the responsibility of the authors and does not necessarily represent the official views of the funding agency. Funding for this study was also provided by a small grant awarded to Dr. Anderson from the Applied Psychology Center at Kent State University.

\section{ORCID iD}

RaeAnn E. Anderson (iD) https://orcid.org/0000-0001-9938-0717

Kelly Cuccolo (iD) https://orcid.org/0000-0002-0358-7113

\section{References}

Abbey, A., BeShears, R., Clinton-Sherrod, A. M., \& McAuslan, P. (2004). Similarities and Differences in Women's Sexual Assault Experiences Based on Tactics Used by the Perpetrator. Psychology of Women Quarterly, 28(4), 323-332. https://doi.org/10.1111/j.1471-6402.2004.00149.x

Anderson, R. E., \& Delahanty, D. L. (2019). Discrepant Responding across Measures of College Students' Sexual Victimization Experiences: Conceptual Replication and Extension. The Journal of Sex Research, 1-12. https://doi.org/10.1080/00224499.2019.1669135

Anderson, R. E., Carstens Namie, E. M., \& Goodman, E. L. (2021). Valid for who? A preliminary investigation of the validity of two sexual victimization questionnaires in men and sexual minorities. American Journal of Criminal Justice, 46(1), 168-185.

Anderson, R. E., Garcia, M., \& Delahanty, D. L. (2021). Test-retest reliabilities of four tactic-first sexual violence history questionnaires. Psychology of Violence. Advance online publication. https://doi.org/10.1037/vio0000384

Anderson, R. E., Goodman, E. L., \& Thimm, S. S. (2020). The Assessment of Forced Penetration: A Necessary and Further Step Toward Understanding Men's Sexual Victimization and Women's Perpetration. Journal of Contemporary Criminal Justice, 36(4), 480-498. https://doi.org/10.1177/1043986220936108

Anderson, R.E., Goodman, E.L. \& Ciampaglia, A.M. (2021) An Initial Test of the Tactic-First and Item-Order Hypotheses: Accounting for Response Discrepancies in Sexual Victimization Questionnaires. American Journal Criminal Justice, 46, 149-167. https://doi.org/10.1007/s12103-020-09584-8

Anderson, R. E., Carstens Namie, E. M., Michel, P. K., \& Delahanty, D. L. (2021). Study title-based framing effects on reports of sexual violence and associated risk factors in college students. Journal of Interpersonal Violence, 08862605211016349 .

Anderson, R. E., Silver, K. E., Ciampaglia, A. M., Vitale, A. M., \& Delahanty, D. L. (2019). The Frequency of Sexual Perpetration in College Men: A Systematic Review of Reported Prevalence Rates From 2000 to 2017. Trauma, Violence, \& Abuse, 22(3), 481-495.. https://doi.org/10.1177/1524838019860619

Basile, K. C., Smith, S., Breiding, M. J., Black, M. C., \& Mahendra, R. (2014). Sexual Violence Surveillance: Uniform Definitions and Recommended Data Elements, Version 2.0. https://www.cdc.gov/violenceprevention/pdf/sv_surveillance_definitionsl-2009-a.pdf

Bell, A. S., Dinwiddie, M., \& Hamby, S. (2018). Gender patterns in intimate partner violence: Results from 33 campus climate surveys based on the Partner Victimization Scale. Sewanee, TN: Life Paths Appalachian Research Center.

Bond, M. A., Stone, A. L., Salcido Jr, R., \& Schnarrs, P. W. (2021). How often were you traumatized? Reconceptualizing adverse childhood experiences for sexual and gender minorities. Journal of Affective Disorders, 282, 407-414. https://doi.org/10.1016/j.jad.2020.12.117 
Buday, S. K., \& Peterson, Z. D. (2015). Men's and Women's Interpretation and Endorsement of Items Measuring Self-Reported Heterosexual Aggression. Journal of Sex Research, 52(9), 1042-1053. https://doi.org/10.1080/00224499.2014.967373

Choudhary, E., Coben, J. H., \& Bossarte, R. M. (2008). Gender and time differences in the associations between sexual violence victimization, health outcomes, and risk behaviors. American Journal of Men's Health, 2(3), 254-259. $10.1177 / 1557988307313819$

Cook, S. L., Gidycz, C. A., Koss, M. P., \& Murphy, M. (2011). Emerging Issues in the Measurement of Rape Victimization. Violence Against Women, 17(2), 2012-2018. https://doi.org/10.1177/1077801210397741

Clark, L. A., \& Watson, D. (2016). Constructing validity: Basic issues in objective scale development. In A. E. Kazdin (Ed.), Methodological issues and strategies in clinical research (p. 187-203). American Psychological Association. doi.org/10.1037/14805-012

Comrey, A. L. (1988). Factor-analytic methods of scale development in personality and clinical psychology. Journal of Consulting and Clinical Psychology, 56(5), 754.

Cornesse, et al (2020) A review of conceptual approaches and empirical evidence on probability and nonprobability sample survey research. Journal of Survey Statistics and Methodology 8:4-36.

Diamantopoulos, A., Riefler, P., \& Roth, K. P. (2008). Advancing formative measurement models. Journal of Business Research, 61(12), 1203-1218. https://doi.org/10.1016/j.jbusres.2008.01.009

DiLillo, D., Fortier, M. A., Hayes, S. A., Trask, E., Perry, A. R., Messman-Moore, T., Fauchier, A., \& Nash, C. (2006). Retrospective Assessment of Childhood Sexual and Physical Abuse: A Comparison of Scaled and Behaviorally Specific Approaches. Assessment, 13(3), 297-312. https://doi.org/10.1177/1073191106288391

Dyar, C., Feinstein, B. A., \& Anderson, R. E. (2019). An Experimental Investigation of Victim Blaming in Sexual Assault: The Roles of Victim Sexual Orientation, Coercion Type, and Stereotypes About Bisexual Women. Journal of Interpersonal Violence, https://doi.org/10.1177/0886260519888209

Erens, B., Burkill, S., Couper, M. P., Conrad, F., Clifton, S., Tanton, C., ... \& Copas, A. J. (2014). Nonprobability web surveys to measure sexual behaviors and attitudes in the general population: a comparison with a probability sample interview survey. Journal of Medical Internet Research, 16(12), e276. doi: 10.2196/jmir.3382

Fisher, B. S., Cullen, F. T., \& Daigle, L. E. (2005). The discovery of acquaintance rape: the salience of methodological innovation and rigor. Journal of Interpersonal Violence, 20(4), 493-500. https://doi.org/10.1177/0886260504267761

Grych, J., \& Hamby, S. (2014). Advancing the measurement of violence: Challenges and opportunities. Psychology of Violence, 4(4), 363-368. https://doi.org/10.1037/a0037886

Hamby, S. (2014). Intimate Partner and Sexual Violence Research: Scientific Progress, Scientific Challenges, and Gender. Trauma, Violence, and Abuse, 15(3), 149-158. https://doi.org/10.1177/1524838014520723

Hamby, S., Sugarman, D. B., \& Boney-McCoy, S. (2006). Does questionnaire format impact reported partner violence rates?: An experimental study. Violence and Victims, 21(4), 507-518.

Hauser, D. J., \& Schwarz, N. (2015). It's a Trap! Instructional Manipulation Checks Prompt Systematic Thinking on “Tricky" Tasks. SAGE Open, 5(2), 215824401558461. https://doi.org/10.1177/2158244015584617

Hlavka, H. R. (2017). Speaking of Stigma and the Silence of Shame: Young Men and Sexual Victimization. Men and Masculinities, 20(4), 482-505. https://doi.org/10.1177/1097184X16652656

Hockett, J. M., Smith, S. J., Klausing, C. D., \& Saucier, D. A. (2016). Rape myth consistency and gender differences in perceiving rape victims: A meta-analysis. Violence Against Women, 22(2), 139-167. https://doi.org/10.1177/1077801215607359

Hulme, P. A. (2007). Psychometric evaluation and comparison of three retrospective, multi-item measures of childhood sexual abuse. Child Abuse and Neglect, 31(8), 853-869. https://doi.org/10.1016/j.chiabu.2007.03.016

Kazdin, A. E. (2016). Methodological issues and strategies in clinical research. American Psychological Association.

Koss, M. P. (1993). Rape: Scope, impact, interventions, and public policy responses. American Psychologist, 48(10), 10621069. https://doi.org/10.1037/0003-066X.48.10.1062 
Koss, M. P., Gidycz, C. A., \& Wisniewski, N. (1987). The scope of rape: Incidence and prevalence of sexual aggression and victimization in a national sample of higher education students. Journal of Consulting and Clinical Psychology, 55(2), 162-170. http://psycnet.apa.orgjournals/ccp/55/2/162

Koss, M. P., Abbey, A., Campbell, R., Cook, S., Norris, J., Testa, M., ... \& White, J. (2007). Revising the SES: A collaborative process to improve assessment of sexual aggression and victimization. Psychology of Women Quarterly, 31(4), 357370.

Krahé, B., Berger, A., Vanwesenbeeck, I., Bianchi, G., Chliaoutakis, J., Fernández-Fuertes, A. A., Fuertes, A., de Matos, M. G., Hadjigeorgiou, E., Haller, B., Hellemans, S., Izdebski, Z., Kouta, C., Meijnckens, D., Murauskiene, L., Papadakaki, M., Ramiro, L., Reis, M., Symons, K., ... Zygadło, A. (2015). Prevalence and correlates of young people's sexual aggression perpetration and victimisation in 10 European countries: a multi-level analysis. Culture, Health \& Sexuality, 17(6), 682-699. doi.org/10.1080/13691058.2014.989265

Krahé, B., \& Vanwesenbeeck, I. (2015). Mapping an agenda for the study of youth sexual aggression in Europe: assessment, principles of good practice, and the multilevel analysis of risk factors. Journal of Sexual Aggression, 2600(August), 1 16. doi.org/10.1080/13552600.2015.1066885

Krebs, C. (2014). Measuring Sexual Victimization: On What Fronts is the Jury Still Out and Do We Need it to Come in? Trauma, Violence, \& Abuse, 15(3), 170-180. https://doi.org/10.1177/1524838014521028

National Research Council. (2014). Estimating the Incidence of Rape and Sexual Assault: Panel on Measuring Rape and sexual Assault in Bureau of Justice Statistics Household Surveys (C. Kruttschnitt, W. D. Kalsbeek, C. C. House, \& D. of B. and S. S. and E. Committee on National Statistics (eds.)). National Academies Press. https://doi.org/10.17226/18605

McCallum, E. B., \& Peterson, Z. D. (2017). Women's Self-Report of Sexual Victimization: An Experimental Examination of the Influence of Race, Mode of Inquiry, Setting, and Researcher Contact. Violence Against Women, 23(7), 850-870. https://doi.org/10.1177/1077801216651338

McCauley, H. L., Silverman, J. G., Jones, K. A., Tancredi, D. J., Decker, M. R., McCormick, M. C., ... \& Miller, E. (2017). Psychometric properties and refinement of the reproductive coercion scale. Contraception, 95(3), 292-298.

Necka, E. A., Cacioppo, S., Norman, G. J., \& Cacioppo, J. T. (2016). Measuring the prevalence of problematic respondent behaviors among MTurk, campus, and community participants. PloS one, 11(6), e0157732.

Parent, M. C. (2013). Handling Item-Level Missing Data. The Counseling Psychologist, 41(4), 568-600. https://doi.org/10.1177/0011000012445176

Peterson, Z. D., Voller, E. K., Polusny, M. A., \& Murdoch, M. (2010). Prevalence and consequences of adult sexual assault of men: review of empirical findings and state of the literature. Clinical Psychology Review, 31(1), 1-24. doi.org/10.1016/j.cpr.2010.08.006

Schuster, I., Tomaszewska, P., Marchewka, J., \& Krahé, B. (2020). Does Question Format Matter in Assessing the Prevalence of Sexual Aggression? A Methodological Study. The Journal of Sex Research, 1-10. https://doi.org/10.1080/00224499.2020.1777927

Schwarz, N., Bless, H., Bohner, G., Harlacher, U., \& Kellenbenz, M. (1991). Response scales as frames of reference: The impact of frequency range on diagnostic judgements. Applied Cognitive Psychology, 5(1), 37-49. https://doi.org/10.1002/acp.2350050104

Schwarz, N., Strack, F., Müller, G., \& Chassein, B. (1988). The range of response alternatives may determine the meaning of the question: Further evidence on informative functions of response alternatives. Social Cognition, 6(2), 107-117. https://doi.org/10.1521/soco.1988.6.2.107

Sigurvinsdottir, R., \& Ullman, S. E. (2016). Sexual Orientation, Race, and Trauma as Predictors of Sexual Assault Recovery. Journal of Family Violence, 31(7), 913-921. https://doi.org/10.1007/s10896-015-9793-8

Strang, E., \& Peterson, Z. D. (2016). Use of a Bogus Pipeline to Detect Men's Underreporting of Sexually Aggressive Behavior. Journal of Interpersonal Violence,35(1-2), 208-232.. https://doi.org/10.1177/0886260516681157

Strang, E., \& Peterson, Z. D. (2017). Unintentional Misreporting on Self-Report Measures of Sexually Aggressive Behavior: An Interview Study. The Journal of Sex Research, 54(8), 1-13. https://doi.org/10.1080/00224499.2017.1304519 
Strang, E., Peterson, Z. D., Hill, Y. N., \& Heiman, J. R. (2013). Discrepant responding across self-report measures of men's coercive and aggressive sexual strategies. Journal of Sex Research, 50(5), 458-469. https://doi.org/10.1080/00224499.2011.646393

Stemple, L., \& Meyer, I. H. (2014). The sexual victimization of men in America: New data challenge old assumptions. American Journal of Public Health, 104(6), e19-e26. https://doi.org/10.2105/AJPH.2014.301946

Straus, M. A., Hamby, S. L., Boney-McCoy, S., \& Sugarman, D. B. (1996). The revised conflict tactics scales (CTS2) development and preliminary psychometric data. Journal of Family Issues, 17(3), $283-316$. https://doi.org/10.1177\%2F019251396017003001

Struckman-Johnson, C., Struckman-Johnson, D., Anderson, P. B., Struckman-Johnson, C., Struckman-Johnson, D., \& Anderson, P. B. (2003). Tactics of sexual coercion: when men and women won't take no for an answer. Journal of Sex Research, 40(1), 76-86. https://doi.org/10.1080/00224490309552168

Sugarman, D. B., \& Hotaling, G. T. (1997). Intimate violence and social desirability: A meta-analytic review. Journal of Interpersonal Violence, 12(2), 275-290. https://doi.org/10.1177/088626097012002008

Swain, S. D., Weathers, D., \& Niedrich, R. W. (2008). Assessing Three Sources of Misresponse to Reversed Likert Items. Journal of Marketing Research, 45(1), 116-131. https://doi.org/10.1509/jmkr.45.1.116

Testa, M., Hoffman, J. H., Lucke, J. F., \& Pagnan, C. E. (2015). Measuring sexual aggression perpetration in college men: A comparison of two measures. Psychology of Violence, 5(3), 285-293. https://doi.org/10.1037/a0037584

Tillman, S., Bryant-Davis, T., Smith, K., \& Marks, A. (2010). Shattering silence: Exploring barriers to disclosure for African American sexual assault survivors. Trauma, Violence, \& Abuse, 11(2), 59-70.

Ullman, S. E. (1996). Correlates and Consequences of Adult Sexual Assault Disclosure. Journal of Interpersonal Violence, 11(4), 554-571. https://doi.org/10.1177/088626096011004007

Walters, M. L., Chen, J., Breiding, M. J., Black, M. C., Basile, K. C., Breiding, M. J., Smith, S., Walters, M. L., Merrick, M., Chen, J., \& Stevens, M. (2011). The National Intimate Partner and Sexual Violence Survey (NISVS): 2010 Summary Report.

Weiss, K. G. (2010). Male sexual victimization: Examining men's experiences of rape and sexual assault. Men and Masculinities, 12(3), 275-298. https://doi.org/10.1177/1097184X08322632 